\title{
A Strategic Approach to Insurability of Risks
}

\author{
by Fedor Nierhaus*
}

1. The subject "limits of insurability" is probably one of the most challenging ones for our industry, both the theory and the practice of insurance and reinsurance. But particularly for strategic decisions in insurance practice, both short and long term, the limits of insurability are of utmost importance. In a doctor thesis on this subject which appeared in my country six years $\mathrm{ago}^{1}$, I read that the practice of insurance was usually ahead of the theory as to the extending of the limits of insurability. But probably to prove that the theory could also be ahead of the practice, the author then rejected the usual criteria of insurability as basically restrictive and pleaded for principal insurability as long as profitability is expected by the insurer.

2. Are there limits to insurability and reinsurability? Are there criteria for insurability and non-insurability as they have been stipulated in the insurance literature for long by authors perhaps less courageous then the one I quoted? Or may it be that it is really only the price, the premium, which in the ultimate determines insurability? I think, and I believe I am in good company amongst responsible insurers and academic writers, that such a concept of insurability is both unrealistic and dangerous. And this I believe is true for three reasons. Firstly, premiums in the non-life insurance field cannot be calculated with adequate precision, at least not in the short term. Secondly, even if adequate fluctuation and security loadings could be calculated, they would not be obtainable because of, thirdly, the immanent oversupply of insurance and also reinsurance and the resulting elastic prices, due as we know to the abstract nature of the product insurance and reinsurance and the time lag between risk assumption and eventual claims payment. Having to observe operating losses of an unprecedented size in many insurance markets and with many reinsurers, we today can experience where such a concept of insurance and the resulting strategy can lead our industry. We have seen what happened in the last decade, when a combination of well known factors, primarily inflation and high interest rates, led to excessive oversupply of insurance and reinsurance and made many insurers and reinsurers let themselves be guided almost exclusively by bottom line thinking, a strategy which disregards insurance and reinsurance technique and largely replaces it by cash flow underwriting.

\footnotetext{
* Executive manager, Munich Reinsurance Company

${ }^{1}$ Lucius, Ralph-René, Die Grenzen der Versicherbarkeit (The Limits of Insurability), Haag und Herchen GmbH, Frankfurt/Main 1979.
} 
One can hope that our industry has learned its lesson that insurers cannot live with a strategy that is determined only by the price but needs also to be determined by the product itself. Thus only a strategy which is guided by the limits of insurability and its criteria will in the long term be successful.

It seems thus not coincidental that Baruch Berliner's book on the limits of insurability ${ }^{2}$ appeared when certain reinsurers increasingly felt that these limits had to be emphasized again.

3. Both the criteria and especially the limits of insurability determined by these criteria certainly cannot be understood as absolute in time and space, but only as open, as gradual, as subject to changes, although some of the criteria of insurability can be conceived as being largely objective in themselves.

Insurance cycles will thus influence these limits. The turnover, the growth potential on the one side, the results on the other side will have an effect. If growth is a problem and normal business stagnates, insurers will look beyond their normal field of activities to grow, particularly if at the same time inflation increases their claims and expenses, as in the years after 1973. The entry of insurers into the field of financial guarantees in the US a number of years ago is a good example of this. If the results, overall or even technical, are still positive, if optimism as to the future results prevails, an insurer will tend to set the limits of insurability wider. If the results become marginal or negative, particularly if the overall results become negative, as in many instances today, if there is pessimism as to the future results, then the limits of insurability will be seen more narrowly. It may be that these limits will only then come back into the minds of the practicing insurer. We experience this today, in a market situation which is changing from an extreme buyer's to a seller's market in many areas, with, however, still a lot of pessimism prevailing as to the results of the immediate future.

What is regarded as insurable and what not at a certain time, is necessarily determined subjectively by the individual insurer and to that extent to be seen from his point of view. Insurability is at the same time determined by the insurers of a market as a whole, and for certain major risks even by the international markets in their entirety. If the insurance and reinsurance markets as a whole are not willing or not able to cope with a risk, it is uninsurable from the point of view of the risk carrier, the one who looks for insurance.

4. I do not want to deal with the criteria for insurability more systematically. This has been done frequently and in detail in the insurance literature. I would like to restrict myself to a few thoughts whose strategic aspects seem to me important in the present situation.

4.1. Firstly, in aiming at an ever growing turnover too many insurers and reinsurers in the days of overcapacity almost consistently disregarded the fact that only unforeseeable occurrences should be insured and reinsured. If we insure an industrial client against all fires, not only against larger, less frequent ones, but also against small, frequent, possibly almost annually occurring fires, this is bound to produce adverse results, because no reasonable insured would buy this cover against frequent small losses unless he gets it at a profit. Insuring

\footnotetext{
${ }^{2}$ Berliner, Baruch, Limits of Insurability of Risks, Prentice Hall, 1982 (in German it is published by Swiss $\mathrm{Re}$ ).
} 
winter losses, freeze losses without adequate deductibles is again insuring almost forseeable events.

Reinsurers also offend against this principle of unforeseeability. If they allow their client companies to retain too little of their business, these clients will have little or no interest in their results and-in I confess a rather wide sense-losses to the reinsurer are almost forseeable, are bound to come. Another example: If in an inflationary climate a reinsurer grants an excess loss protection for long-tail liability business without a stability clause, that is without the excess point for old but not yet settled losses being adjusted with inflation, then the resulting losses to the reinsurer are entirely forseeable. One further example: If a reinsurer grants catastrophe excess loss protection at such a low level of cat astrophe exposure, that for example storms or winter losses will affect him almost annually, this again is reinsuring the forseeable. You might say this is also a question of price. This is correct, but again, who will pay more for forseeable losses than what these losses will cost him - and it would be more, as the reinsurer would at least have to add his costs to the loss expectancy?

4.2. Secondly, there are limits to the insurability of major risks and catastrophic events ${ }^{3}$. For certain of these, even on a worldwide basis, a balancing of risk and results in space and time is not possible. From the point of view of the individual insurer's strategy, the crucial problem is not to overexpose its net assets. From the point of view of a market as a whole, the strategic problem is that the market might not be able to provide the necessary capacity or, worse, that it might have overexposed its combined net market assets.

This shows above all how indispensable it is for any insurer or reinsurer to know the risks, particularly the accumulations, he assumes. As far as earthquake and storm insurance is concerned, there is still a large number of markets in which insurers and proportional reinsurers assume catastrophe exposures without knowing how much they have assumed in the aggregate, where from - and if I may mention this already here, at what price. With the exception of motor insurance, there is no class where an insurer would grant unlimited cover per risk. If he sells storm and earthquake insurance, he naturally will limit his liability per individual risk. He knows that these risks are not independent of each other as far as storm or earthquake are concerned, but may accumulate. To my knowledge only in Switzerland and Japan do insurers as a whole endeavour to limit their overall market liabilities from natural catastrophes. In the country with the largest natural catastrophe exposure in the world, the US, hardly any exact control and no event limitation exists, although some insurers and most reinsurers try at least to control their exposures by sophisticated estimation procedures. You will know that in the US, for many years, efforts have been made by insurers to bring in the Government as a reinsurer of last resort in the case of a major natural catastrophe. But we should realize that this means the overt admission that the market as a whole has overcommitted itself. This is primariliy due to the fact that per event uncontrolled and therefore also unlimited liabilities were assumed.

\footnotetext{
${ }^{3}$ See also for the following, Gerathewohl, Klaus und Nierhaus, Fedor, Grenzen der Versicherbarkeit von Katastrophenrisiken (Limits of Insurability of Catastrophe Risks), Zeitschrift für Versicherungswesen, 1980, p. 535 (appeared in French in Argus International 1981, p. 315; an English version is available at Munich $\mathrm{Re}$ ).
} 
That this can happen is probably due to the same phenomenon which makes private persons and industrial concerns rather worry about the frequent small claims area than the infrequent shock type loss.

It is not astonishing that it was the reinsurers which on a worldwise basis tried to make their client companies aware of the necessity for insuring catastrophe perils only on a fully transparent and controlled basis. As catastrophe exposures from any one market accumulate in the portfolios of reinsurers, they have to take the lead in this field of accumulation control and limitation. We all have to realize in this context, which is most important, that the limits of reinsurability, in other words the capacity of the reinsurance markets, largely determine the limits of insurability as far as major risks and catastrophes are concerned.

Reinsurers therefore, even more so than insurers, must make certain that they can control their own exposures. They cannot rely on reinsurance or, as we say, retrocession, as many insurers perhaps rightly or wrongly may do. Reinsurers must also realize that as long as they assume intransparent catastrophe exposures in proportional reinsurance, or more crudely expressed, as long as they assume unknown, uncontrolled catastrophe exposures (frequently without knowing the premium they get for it or whether they get any premium at all, if I may add this again here), as long as reinsurers do this, their insurance clients may continue to try and control their catastrophe exposures by reinsurance and not by controlling their gross writings. This is a most crucial stategic fact.

Allow me as a reinsurer to say that if this situation still exists, this was and is due to the fact that almost two decades of overcapacity in reinsurance prevented even responsible reinsurers from succeeding in changing this situation, which they tried and tried hard as you may know.

Let me add that, also from an insurer's point of view, controlling catastrophe exposures by reinsurance without making certain that the reinsurers know the liabilities they assume, is a very doubtful achievement. Many part time reinsurers, uninformed or innocent, may overcommit themselves substantially. They may themselves rely on reinsurance, on retrocession, but will they purchase enough retrocession, and will their retrocessionaires not equally overcommit themselves if they assume such unknown liabilities on a proportional basis?

It is more than obvious that catastrophe insurance from the point of view of a responsible insurer as well as reinsurer, requires the strictest accumulation control based on uniform zoning. This again requires that such catastrophe insurances are covered by special endorsements, and let me say this already here, are rated separately from other perils. The reinsurer must receive regular, reliable information on the liabilities assumed by him and must get this business separately accounted for.

If reinsurers cannot achieve this, they must, by applying their own reinsurance instruments, make certain that they reinsure only controllable exposures. This may mean imposing loss occurrence limits in proportional treaties, that is catastrophe loss limits per event. The only alternative, particularly if also the premium side is unsatisfactory, would be to deny proportional reinsurance and offer only catastrophe excess loss reinsurance. In catastrophe excess loss reinsurance the reinsurer can limit his liability and can price the cover he gives himself, independently from the original inadequate price.

Allow me a word with regard to political risks. Compared with the perils of earthquake and storm, for political risks such as riots, civil commotion and acts of terrorism, the probability and the severity, the likely size of losses, cannot really be assessed at all. If insurance 
density is low, this may not be a problem. But if cover is given widely, it will be a problem. Insurers will have to apply the instruments available to them, such as event or better annual loss limits per policy and short term cancellation provisions to protect them in case a situation of political unrest escalates. If insurers do not do this, reinsurers again may be forced to apply similar instruments in their proportional reinsurance treaties, irrespective of whether the direct insurer acts accordingly versus his clients.

What is to happen if the limits of insurability are reached for a market as far as possible catastrophes are concerned, or worse, if these limits are already exceeded or even worse than that perhaps if the assumed liabilities are not controlled or as in the case of political risks are not really controllable? The insurance industry of a market in such a situation might consider approaching its Government as in the US. It might also impose a market loss limit as was done in Switzerland for natural perils, where individual claims could be prorated if a market loss exceeded this limit. To do nothing would certainly not be a very responsible approach.

If certain major risks or catastrophe exposures, particularly today, as we almost daily see, are not insurable or reinsurable, this may, however, not be due to genuine capacity problems but just to the fact that either the premiums or the conditions are inadequate.

In the third party liability field, above all for US products liability exposures, a number of catastrophic events such as Asbestosis, Agent Orange and now Union Carbide have led to such an uncertainty as to where the insurance industry stands as far as its overall liabilities are concerned, that the capacity on the insurance and reinsurance side seems to have shrunk dramatically, and this inspite of now almost roaring premium increases. It is an understandable strategic decision if an insurer is not willing to enter into long-tail liabilities, the extent of which, because of the judicial system in the US, is not at present controllable. Let us think alone of punitive damages awards far beyond policy limits.

4.3. Thirdly, it might be acceptable, if an insurer (for whatever reason) tolerate inadequate premiums, only as a very short term strategy. Inadequate premiums can very quickly make a risk uninsurable, if it is a really major risk needing worldwide capacity. For the majority of even larger risks, but certainly medium-sized and small risks, the limits of insurability as to premiums become obvious only when underwriting losses, or maybe only when operating losses result which affect the insurers so much that they have to change their policy and start increasing rates.

Many aspects could be discussed in the context of the strategic approach to insurability steering the premium level. One aspect would be the extent to which investment income could be taken into account and in which classes of insurance. An insurer in an industrialized country today cannot and will not ignore the changed relative weight, the changed interdependence between underwriting results and investment income. ${ }^{4}$

Another aspect which could be dealt with is how an insurer can use reinsurance not only to increase his capacity but also or maybe only to influence his own pricing, the level of his premium rates. Berliner in his book makes a number of quite startling statements in this context, startling for the naive observer who still believes that the relationship between the

\footnotetext{
4 More regarding this subject in Gerathewohl, Klaus "Can We Say Goodbye To Underwriting Profit?" Best's Review, October 1984, p. 32.
} 
insurer and his reinsurer is really still one of fully sharing each other's fortunes and of partnership. Let me quote Berliner: The lower the premium for large risks, the more the insurer will have to reinsure. Or: If the reinsurance is overplaced, a lower reinsurance price could have been achieved by the insurer. Or: If the insurer gets a reinsurance commission exceeding his cost, he could in renouncing his profit on the cost side reduce his premium and become more competitive. We all know by now this so called "gearing factor", the use of a profit on the commission side to reduce premium rates, either to defend an account or to aggressively acquire business. And again Berliner: If reinsurance reduces fluctuations, the insurer in turn can reduce his fluctuation loading and thus his rates and become again more competitive.

Berliner's unpleasant but rational statements can be supplemented by a few more unpleasantnesses for the reinsurer as far as premium strategies of insurers are concerned. One: if an insurer, as is legitimate, reinsures more in strongly fluctuating classes such as industrial fire than in less fluctuating classes such as motor or other personal lines, he reduces the weight of say industrial fire in his overall portfolio and might even live quite happily with net losses in this class. If industrial fire, to use again this example, represents as it often does only about $5 \%$ of an insurer's total gross premium over all classes and only $1-2 \%$ of his net premium after reinsurance, net losses will have too little weight to force the insurer to increase his industrial fire rates, even if the reinsurers reduce reinsurance commissions much below cost. Two: Cash flow underwriting becomes somewhat less dangerous for the insurer if he heavily reinsures strongly fluctuating classes and thus reduces or eliminates these fluctuations. If these heavily reinsured classes are as often also producing less investment income than the retained business, the insurer's overall investment income at the same time gains in relative weight against premiums. Three: All this shortens for the insurer also the period needed for balancing his net results in time. Four: If in addition the insurer reinsures more in bad and less in good days, this again shortens for him the period necessary for balancing his net results in time.

Let me resist the temptation to paint you the reverse picture on the reinsurance side. It is too obvious. It is equally obvious that, to stay with our example, reinsurance of industrial fire in such a situation would become seriously impaired in the medium and long term, unless the reinsurer over all classes was on an equal footing with the insurer, which almost certainly he would not be. If the insurability of a class of business depends on its reinsurability, such a situation cannot last. Classes of insurance with strongly fluctuating results which are thus heavily reinsured, such as industrial fire, must of necessity produce balanced results for the reinsurer over a certain period of time. This requires either corresponding cyclical rate adjustments, or it requires that the reinsurer detaches his price from the inadequate original price and charges his own correspondingly higher price. A responsible insurer who takes a long term view, should take this into account when deciding his premium strategy. Even if he does not, he may still find second and third class reinsurers, but very likely not first class security. If he wants first class security, he should change his strategy.

Let me come to another point. Reinsurance in classes which even over a certain period of time produce overall positive results only with the help of investment income, requires an equal footing for the reinsurer also as far as the investment income from this business is concerned.

Let me for completeness' sake mention that also as far as catastrophe perils are concerned, the proportional reinsurer in the medium and long term can equally only accept original premium rates which are adequate; otherwise he will have to charge his clients higher than original rates, equal to the ones he can charge in non-proportional reinsurance. 
The insurer in his premium strategy should take all this into account before continuing to charge too low rates- but he should take this into account not just today, in a changed competitive situation, with a seller's market instead of a buyer's market in many fields, which makes it easier for reinsurers to object to such strategies amongst their client companies.

4.4. Fourthly, let me deal shortly with two further aspects in the context of insurability, two aspects which affect in particular also the reinsurer. One such aspect is the tendency of insurers to sell all risks and multi-line covers also in the industrial and commercial field which is frequently heavily reinsured. This is a problem which concerns various criteria of insurability, the price, the unforseeability, the clear definition and limitation of coverage and lastly the possibility of manipulations. In the relation between client and insurer such all risks policies mean that the responsibility for risk identification is transferred from the client to the insurer and if the insurer reinsures, then from the insurer to the reinsurer, who is the furthest away from the risk. This should not and cannot really be so. If not the insurer, then the reinsurer will have to interfere to reestablish reinsurability and thus insurability.

I have mentioned already the judicial system in the US and the problems resulting from it for insurers and reinsurers. The courts in the US presuppose insurance if they make their awards in favour of insureds and maybe even presuppose reinsurance if they make such awards against smaller insurers, that is their awards beyond policy limits or their awards for punitive damages. If clear policy wordings do not protect an insurer and his reinsurer any more, if the judicial system makes insurers pay clearly beyond what they intended to cover, the insurability and reinsurability of risks are not warranted any more. For a reinsurer to protect an insurer against punitive damages awarded because the insurer did not settle a claim in due time, is actually not reinsurance but is insurance which the insurer should not give; the reinsurer would also be protecting the insurer against a business risk from which the insurer, alone for ethical reasons, should not be relieved, at least not in many instances. We should not forget that the insurance of punitive damages in a number of states of the US is actually regarded as illegal.

5. Let me conclude with a few words on reinsurability as opposed to insurability. So far I have spoken of reinsurability as part of insurability, as providing and supporting insurability. To the extent that an insurer can carry the risk himself, reinsurability is not required. Above all insurability depends on reinsurability as far as major risks and catastrophe exposures are concerned, for which a balancing of risk is only possible with the help of the international reinsurance markets. In this context reinsurers in their strategies have to realize a most important fact: To the extent that they do not carry the risk themselves, but want to spread it further, as many do, they themselves depend on reinsurance, on retrocession as we say. The retrocession markets, however, are much narrower than the reinsurance markets, react usually much more quickly and are frequently also more restrictive, not only on bad results but also on major losses and catastrophes. The retrocession markets react also not only as far as price is concerned, but also as to capacity. The reinsurer therefore cannot take it for granted that his retrocessions will be reinstated or renewed after major losses. This may apply to political risks for countries with escalating political unrest. The limits of reinsurability, one could say, may thus be reached earlier than the limits of insurability, whereby it is questionable whether the reinsurance markets as a whole would be able to bridge the gap from within their own resources. Reinsurers in their strategic decisions thus have to carefully watch that there is congruence 
between the protection they sell and the protection they buy - a problem which naturally exists equally for the insurer in his relationship with his clients on the one side, and with his reinsurers on the other.

Let me finally come to what I may call the reinsurability of insurers. Reinsurability of insurers in this sense means a certain quality of an insurer to qualify as a reinsured. Reinsurance requires a special relationship. It is not mass business - selling and buying reinsurance is thus not like selling and buying a mass product. The insurer in his very own interest should look for first class security and continuity. But also the reinsurer needs a financially and let's call it morally secure insurer as his client, who equally provides continuity. Continuity as required by the reinsurer means that his insurer should not just want him for bad days but should be prepared to let him earn losses back. The insurer should regard reinsurance as a balancing of fluctuations and not just as an assumption of losses in bad days. The reinsurer thus also needs an insurer who is prepared to accept that a reinsurer who assumes high losses in bad days needs high profits in better days. A reinsurance strategy in which an insurer sees reinsurance just as a short-term means to gain a profit would make this insurer unreinsurable - or would make it necessary to treat him in an entirely different way: with terms loaded for the short-term nature of the relationship, for the non-continuity offered to the reinsurer; in addition to such loadings the reinsurer would have to demand the strictest possible control, compensating for the lack of partnership. All this is not in the interest of the reinsurer and much less in the interest of an insurer and should not be considered as an acceptable strategy by any insurer as far as reinsurance is concerned.

The reinsurer fulfills the function of assuming risks and spreading them further to some extent and thus providing a balancing of risks in space and time which only reinsurance can provide. But the reinsurer can extend the limits of insurability for his clients only within the limits of reinsurability and with reinsurable clients.

6. The criteria of insurability and reinsurability are of such importance to our industry, that almost all aspects which presently are topical and discussed in the context of "back to basics", back to sound underwriting, could be discussed also within the framework of these criteria of insurability. In this sense I wanted to demonstrate how the adherence to such criteria could help to bring our industry, so shaken and worried in many markets and fields at present, back to more sanity, back to more lasting prosperity. 